\title{
The Effects of Patient Evaluation Times on Diagnosis in Crowded Emergency Services
}

\author{
Kalabalık Acil Servislerde Hasta Değerlendirme Sürelerinin Tanıya Etkisi
}

\author{
iD Ahu Özkaya Karsandı1, (iD Seda Özkan², iD Kadir Dibek ${ }^{3}$, iD Engin Deniz Arslan ${ }^{4}$
}

1 - Gölbaşı Şehit Ahmet Özsoy Devlet Hastanesi, Acil Tıp Kliniği Ankara, Turkey. 2 - İstanbul Üniversitesi-Cerrahpaşa, Cerrahpaşa Tıp Fakültesi, Acil Tıp Anabilim Dalı, İstanbul, Turkey. 3 - Bandırma Devlet Hastanesi, Acil Tıp Kliniği, Bandırma, Turkey. 4 - Antalya Eğitim ve Araştırma Hastanesi, Acil Tıp Kliniği, Antalya, Turkey.

\begin{abstract}
Objective: The aim of this study is to compare the duration of limited physical examination with detailed physical examination in patients admitted to the emergency department and the accuracy rate of pre-diagnoses after these examinations. In addition, it is to evaluate the effectiveness of the complaints, physical examination and tests at the diagnosis stage of the patients.

Material and Method: 500 yellow field patients who applied to the emergency department were included in the study. The demographic characteristics, complaints and physical examination findings of the patients were recorded. Preliminary diagnoses considered based on complaints, limited and detailed physical examination findings were recorded. Definitive diagnosis and other diagnoses were compared statistically.

Results: The average age of the patients was $48.76 \pm 18.66$ and $44 \%$ were male. Accuracy of preliminary diagnoses intended for complaint (Group 1), limited examination for complaint (Group 2) and detailed examination (Group 3) rates were respectively $64.6 \%, 76 \%$ and $89.2 \%$. There was a statistically significant difference between the 3 groups $(p<0.001)$. Limited examination for complaint and detailed examination time averages were respectively $2.53 \pm 0.87$ min and $7.00 \pm 1.80 \mathrm{~min}$. Both physical examination times were statistically compared with each other and a significant difference was found between them $(p<0.001) .15 .4 \%$ of the patients were hospitalized. Constitute a large majority of the admissions to the hospital 405 (81\%) has been discharged from the hospital.
\end{abstract}

Conclusion: In patients admitted to the emergency department, the rate of correct diagnosis increases as the duration of patient evaluation and examination increases.

ÖZET

Amaç: Acil servise başvuran hastalarda şikayete yönelik kısıtll muayene ile ayrıntılı fizik muayene sürelerini ve bu muayeneler sonrasında oluşan ön tanıların doğruluk oranını karşılaştırmak ve hastaların tanı koyma aşamasında şikayet, fizik muayene ve tetkiklerin ne düzeyde etkili olduğunu değerlendirmektir.

Gereç ve Yöntem: Acil servise başvuran 500 sarı alan hastası çalışmaya dahil edildi. Hastaların demografik özellikleri, şikayetleri, fizik muayene bulguları kaydedildi. Şikayet, kısıtlı ve ayrıntıll fizik muayene bulgularına göre düşünülen ön tanılar kaydedildi. Kesin tanı ile diğer tanılar istatistiksel olarak karşılaştırıldı.

Bulgular: Hastaların yaş ortalaması $48.76 \pm 18.66$ ve \%44'ü erkekti. Hastanın şikayetine göre (Grup 1), şikayete yönelik yapılan kısıtlı fizik muayene (Grup 2) ve ayrıntıll fizik muayeneye göre ön tanıların (Grup 3) doğruluk oranı sirastyla \%64.6, \%76 ve \%89.2 saptandl. Her 3 grup arasinda istatiksel olarak anlaml fark bulundu $(p<0.001)$. Hastaların şikayete yönelik kisıtlı fizik muayene zamanı ortalaması $2.53 \pm 0.87$ dakika, ayrıntıl fizik muayene zamanı ortalaması ise $7.00 \pm 1.80$ dakika tespit edildi. Her iki fizik muayene zamanı aralarında anlaml fark vard $(p<0.001)$. Hastaların kliniklere yatış oranı \% 15.4 olarak saptandl. Hastaların \%81'i $(n=405)$ acil servisten taburcu edildi.

Sonuç: Acil servise başvuran hastalarda, hasta değerlendirme ve muayene süresi arttıkça doğru tanı konma oranlarl artmaktadir.
Keywords:

Crowded emergency,

Triage,

Anamnesis,

Physical examination

Anahtar Kelimeler:

Kalabalı acil,

Triyaj,

Anamnez,

Fizik muayene

\section{GíRIŞ̧}

Acil servis kalabalığı ülkemizde ve dünyada sağlık bakım kalitesini etkileyen, mortalite ve morbiditeyi arttıran ciddi bir halk sağlığ1 sorunudur $(1,2)$. Son yıllarda acil servis kalabalığı acil servislerin yeni hastalığı olarak adlandırılmaktadır (3). Acil servislere başvuran hastaların önemli bir kısmının gerçekten acil sağlık hizmeti almasını gerektiren bir durumu olmadığı ve bu hastaların oluşturduğu kalabalık nedeni ile acil tedavisi gereken hastalara sunulan hizmetin kalitesinin düştüğü için bu durum hem hizmet sunan acil servis çalışanını hem de hizmet alan hastayı olumsuz etkilemektedir (4).

2011 WHO istatistiklerine göre ABD'de 1000 kişi başına düşen doktor sayısı 2.7 iken İngiltere'de 2.1 ve Türkiye'de 1.5, dünya ortalaması ise 3.03 olarak bulunmuştur. Acil servislerde hasta başına düşen doktor sayısının az olması, giderek artan hasta sayıları ve kalifiye eleman eksikliği hasta değerlendirilme süresini kısaltmaktadır (4).

Received: $26.01 .2021 \quad$ Accepted: 12.02.2021

Correspondence: Seda Özkan, İstanbul Üniversitesi-Cerrahpaşa, Cerrahpaşa Tıp Fakültesi, Acil Tıp Anabilim Dalı, Fatih, İstanbul, Türkiye. E-mail: sedacil@gmail.com

Cite this article as: Karsandi AO, Ozkan S, Dibek K, Arslan ED. The Effects of patient evaluation times on diagnosis in crowded emergency services. Phnx Med J. 2021;3(1):5-10. 


\section{GEREÇ VE YÖNTEM}

Bu çalışma, "Dünya Tıp Birliği Helsinki Bildirgesi" esaslarına uyularak, Ankara Dışkapı Eğitim ve Araştırma Hastanesi Klinik Araştırmalar Etik Kurulu onayı (Tarih:17.04.2017, Sayı:37/19) alınarak araştırma kuralları doğrultusunda yapıldı. 10 ay süresince acil servise travma dışı medikal nedenlerle başvuran 18 yaş ve üzeri hastalar çalışmaya alındı. Çalışmaiçin gerekli veriler hastaların dosyaları ile bilgisayar tabanlı hasta kayıtları incelenerek ve hasta veya hasta yakını ile görüşülerek elde edildi. Acil Servis'e başvuran 266610 hasta içerisinden randomize olarak seçilen 500 sarı alan hastası çalışmaya dahil edildi. Bu hastaların demografik özellikleri, şikayetleri, fizik muayene bulguları incelendi. Hastaların ayrıca öykü, ko-morbid hastalıklar, kullandığı ilaçlar, istenen laboratuvar ve görüntüleme bulguları da kaydedildi. Hastaların sonuçl-anması ve 24 saat sonrasındaki durumu, hastanın şikayet tekrarı, başka şikayetinin olması, aynı merkeze tekrar başvuru yapıp yapmadığ 1 , komplikasyon gelişip gelişmediği ve mortalite durumu analiz edildi.

Dişlama kriterleri:

1. 18 yaşın altı hastalar

2. Travma hastaları

3. Kesin tanı almayan hastalar

4. Acil servise ölü veya arrest olarak getirilen hastalar

5. Hemodinamisi stabil olmayan hastalar

Değerlendirme aşamasında hastalar 4 gruba ayrıldı.

1. Grup; hastanın şikayetine yönelik ön tanı

2. Grup; hastanın şikayeti ve şikayete yönelik kısıtlı fizik muayenesine göre oluşan ön tanı

3. Grup; hastanın şikayeti ve ayrıntılı fizik muayenesine göre oluşan ön tanı

4. Grup; hastanın şikayeti, fizik muayenesi ve tetkiklerininsonucuna göre aldığ1 kesin tanı Hastanın acil serviste yapılan tetkikler sonucunda aldığ kesin tanı belirlendikten sonra bu 4 grubun ön tanıları istatistiksel olarak birbirleriyle karşılaştırıldı. Hastalar 3 yıllık deneyimi olan tek acil tıp asistanı tarafindan değerlendirildi.

\section{İstatiksel Analiz}

İstatistiksel analizler SPSS (Statistics Program for Social Scientists, SPSS Inc.,Chicago, IL, USA) 17.0 programı ile yapıldı. Sayısal değişkenler ortanca (minimum-maksimum) veya ortalama \pm standart sapma şeklinde ifade edildi. Kategorik değişkenler sayı ve yüzde ile gösterildi. Kolmogorov-Smirnov testi ile normallik analizi yapıldı. Tanı grupları normal dağılıma uydukları yukarıda belirtilen ilk 3 grubun karşılaştırılmasında Friedman testi kullanıldı. Daha sonra verilerin post hoc analizinde Wilcoxon testi uyguland. Fizik muayene zamanlarının değerlendirilmesinde gruplar normal dağılıma uydukları ve bağımlı oldukları için iki gurubun karşılaştırılmasında eşleştirilmiş $\mathrm{t}$ testi uygulandı. Anlamlılık düzeyi $\mathrm{p}<0.05$ olarak belirlenmiştir.

\section{BULGULAR}

Çalışma süresi boyunca Dışkapı Yıldırım Beyazıt EAH Acil Servisine toplam 266.610 hasta başvurmuştur. Çalışmaya alınan 500 hastanın yaş ortalaması $48.76 \pm 18.66$ (18-91) olarak saptandı. Vakaların \% 44'ü erkek (n=220), \%56's1 $(n=280)$ ise kadındı (Tablo 1). Hastaların genel durumu iyi, orta ve kötü olarak gruplandırıldığında \%71.4'ünün genel durumu iyi (n=357), \%25.8'inin genel durumu orta (n:129) ve \%.28'inin genel durumu kötü $(\mathrm{n}=14)$ olarak bulundu.

Hastaların alışkanlıkları sorgulandığında \%40.4 oranında sigara $(n=202), \% 1.6$ alkol $(n=8)$ ve $\% 1.4$ oranında uyuşturucu madde (n=7) kullanım öyküsü mevcuttu. Hastaların \% 56.6'nın ise $(n=283)$ herhangi bir alışkanlık öyküsü yoktu. Hastaların \%23'ünde ( $\mathrm{n}=119)$ Hipertansiyon (HT), \% 16.6'sında $(\mathrm{n}=83)$ Koroner Arter Hastalığ 1 (KAH), \% 2.2'sinde $(\mathrm{n}=11)$ Kronik Böbrek Hastalığ 1 (KBH), \% 16.4'ünde $(\mathrm{n}=82)$ Diabetes Mellitus (DM), \%5.5'inde $(n=28)$ Kronik Obstruktif Akciğer Hastalığı (KOAH), \% 4'ünde $(n=20)$ geçirilmiş Serebrovasküler Hastalık (SVO) öyküsü, \%18.2'inde (n=91) diğer hastalıklar mevcut idi (Tablo 1).

Tablo 1: Hastaların demografik özellikleri ve vital bulguları

\begin{tabular}{ll}
\hline Değişkenler & \\
\hline Kadın; n (\%) & $280(56)$ \\
Erkek; n (\%) & $220(44)$ \\
Yaş; yıl, ortalama \pm SD (min-max) & $48.76 \pm 18.66($ \\
Sistolik KB; mmHg, ortalama \pm SD & $18-91)$ \\
(min-max) & $127.51 \pm 21.35$ \\
Diyastolik KB; mmHg, ortalama \pm SD & $(70-240)$ \\
(min-max) & $73.43 \pm 12$ \\
Nabız / dk, ortalama \pm SD & $(40-160)$ \\
\hline (min-max) & $83.4 \pm 12.08($ \\
\hline Oksijen satürasyonu, ortalama \pm SD & $37-156) 95.4 \pm 2.46$ \\
(min-max) & $(74-100)$ \\
\hline Kronik Hastalıklar & $\mathbf{n}(\%)$ \\
\hline Hipertansiyon & $119(23)$ \\
\hline Diabet & $\mathbf{8 2}(16.4)$ \\
\hline KAH & $\mathbf{8 3}(16.6)$ \\
\hline KOAH & $28(5.5)$ \\
\hline KBYğer & $11(2.2)$ \\
\hline SVO & $20(4)$ \\
\hline
\end{tabular}


Hastaların \%21.8'inde $(n=109)$ kronik hastalıklar ve malignite açısından aile öyküsü pozitifti. Hastalarda başvuru nedeni, \%44'ünde ( $\mathrm{n}=220)$ kronik hastalıklarından bağımsız yeni bir hastalık tanısına, \%27.6'sında $(n=138)$ kronik hastalıklarının sık görülen bir komplikasyonuna, \% 6.6'sında $(n=33)$ kronik hastalıklarının nadir görülen bir komplikasyonuna bağlı idi. Hastaların en fazla \%29.8 ile kardiyovasküler sistem ile ilgili şikayetleri olduğu görüldü (Tablo 2). Hastaların tam sistemik muayenesi yapıldığında ise; hastaların \%7.4'ünde $\mathrm{KBB}(\mathrm{n}=37), \% 1.6$ baş-boyun $(n=8), \% 0.6$ göz $(n=3), \% 9.2$ solunum sistemi $(n=46), \%$ 4.3 kardiyovasküler sistem $(n=21), \% 31.4$ gastrointestinal sistem $(n=157), \% 5.6$ sinir sistemi $(n=28), \% 0.2$ genital sistem $(n=1), \% 2.6$ üst ekstremite $(n=13)$ ve $\% 3.6$ alt ekstremite $(\mathrm{n}=18)$ 'de pozitif muayene bulgusu saptand1. Hastalara en fazla \%72.4 oranında tam kan tetkiki istenmiştir bunun da \%46'sı normal sonuçlanmıştır. Diğer tetkiklerin istenme ve normal çıkma oranları tablo 3 'de gösterilmiştir.

Hastaların \%11.4'ü $\quad(n=57)$ ambulans ile getirildi. Ambulans ile gelen hastaların \%28.7'si (n=16) kırmızı alana alınırken \%64.9'u $(n=37)$ sarı alana alındı. Hastaların \%7.02'si ise $(n=4)$ ayaktan takip edilerek taburcu edildi (Tablo 4). Triyaj yapıldıktan sonra hastaların doktorla temas süreleri ortalama 3.5 dakika olarak bulundu (1-10 dk). Ön tanı konulduktan sonra hastaların acil serviste kalış süreleri ortalama 8.17 (0.5-72) saat tespit edildi.

Hastaların \%81'i ( $\mathrm{n}=405)$ acil serviste tektik ve tedavileri yapılarak taburcu edildi. Hastaların \%15.4'ü $(n=77)$ yatış endikasyonu olup hastaneye yatırıldı. Acil servisten taburcu edilen hastaların içinde \%5.9'u ( $\mathrm{n}=24)$ yatış endikasyonu olmakla birlikte hastaneye yatırılamayan hastalardı. Geriye kalan \%94'ü $(n=381)$ acil yatış endikasyonu olmayı, acil serviste tedavisi tamamlandiktan sonra taburcu edildi (Tablo 5).

Çalışmaya aldığımız hastaların şikayete yönelik kısıtl fizik muayene zamanı ortalaması $2.53 \pm 0.87$ dakika (1-6) fizik muayene zamanı ortalaması $2.53 \pm 0.87$ dakika (1-6) olarak tespit edildi. Ayrıntılı fizik muayene zamanı ortalaması ise $7.00 \pm 1.80$ dakika (4-14) olarak tespit edildi. Her iki fizik muayene zamanı birbiri ile istatistiksel olarak karşılaştırıldı, aralarında anlamlı fark tespit edildi $(\mathrm{p}<0.001)$ (Şekil 1).

Hastanın şikayeti, anamnez ve vital bulgularına göre yapılan ön tanının doğruluk oranı \%64.6 (n=323) idi. Hastanın şikayeti ve şikayetine yönelik kısıtlı fizik muayene sonrası ön tanının doğruluk oranı \%76 (n=380) idi. Hastanın şikayeti göz önüne alınarak ve tam sistemik muayenesi yapılarak konulan ön tanıların doğruluk oranına bakıldığında ise \%89.2 $(\mathrm{n}=446)$ oranında doğru tanı konulduğu görüldü. Her 3 grup arasında istatiksel olarak anlamlı fark bulundu $(\mathrm{p}<0.001)$. Tüm ikili gruplar arasında anlamlı fark tespit edildi (Tablo 6).
Tablo 2: Hastaların başvuru şikayetleri ve şikayetlerin sistemlere göre dağılımı

\begin{tabular}{|c|c|}
\hline Başvuru Şikayetleri & n (\%) \\
\hline Ataksi & $2(0.4)$ \\
\hline Ateş & $12(2.4)$ \\
\hline Baş ağrıs1 & $9(1.8)$ \\
\hline Baş dönmesi & $21(4.2)$ \\
\hline Bel ağrısı & $1(0.2)$ \\
\hline Boğaz ağrısı & $2(0.4)$ \\
\hline Bulantı & $13(2.6)$ \\
\hline Çarpıntı & $7(1.4)$ \\
\hline Diş ağrısı & $1(0.2)$ \\
\hline Dispne & $17(3.4)$ \\
\hline Dizüri & $10(2)$ \\
\hline Eklem ağrısı & $14(2.8)$ \\
\hline Göğüs ağrısı & $79(15.8)$ \\
\hline Görme bozukluğu & $2(0.4)$ \\
\hline Halsizlik & $11(2.2)$ \\
\hline Hematemez & $2(0.4)$ \\
\hline Hematokezya & $1(0.2)$ \\
\hline Hemiparezi & $12(2.4)$ \\
\hline Hemoptizi & $2(0.4)$ \\
\hline İshal & $4(0.8)$ \\
\hline Kabızlık & $1(0.2)$ \\
\hline Karın ağrısı & $125(25)$ \\
\hline Kasık ağrısı & $2(0.4)$ \\
\hline Konuşma bozukluğu & $6(1.2)$ \\
\hline Kusma & $40(8)$ \\
\hline Öksürük & $24(4.8)$ \\
\hline Senkop & $22(4.4)$ \\
\hline Sirt ağrısı & $17(3.4)$ \\
\hline Yan ağrıs1 & $39(7.8)$ \\
\hline Yüzde uyuşma & $2(0.4)$ \\
\hline Sistemler & n (\%) \\
\hline Kulak burun boğaz & $59(11.8)$ \\
\hline Baş boyun & $55(11)$ \\
\hline Göz & $3(0.6)$ \\
\hline Solunum Sistemi & $126(25.2)$ \\
\hline KVS & $149(29.8)$ \\
\hline Gís & $267(53.4)$ \\
\hline Sinir sistemi & $57(11.4)$ \\
\hline Ürogenital & $21(4.2)$ \\
\hline Ekstremiteler & $62(12.4)$ \\
\hline
\end{tabular}


Tablo 3: Hastalarda Tetkiklerin İstenme Oranı

\begin{tabular}{|c|c|c|c|c|}
\hline \multirow{2}{*}{ Tetkik } & \multicolumn{2}{|c|}{$\begin{array}{c}\text { İstem Yapılan } \\
\text { Hasta }\end{array}$} & \multicolumn{2}{|c|}{$\begin{array}{c}\text { Normal } \\
\text { Sonuçlanma }\end{array}$} \\
\hline & $\mathbf{n}$ & $\%$ & $\mathbf{n}$ & $\%$ \\
\hline Hemogram & 362 & 72.4 & 230 & 46 \\
\hline Biyokimya & 313 & 62.6 & 231 & 46.2 \\
\hline Kardiyak enzim & 224 & 54.8 & 186 & 37.2 \\
\hline Tam idrar tetkiki & 205 & 51 & 71 & 14.2 \\
\hline Direk grafi & 306 & 61.2 & 227 & 45.4 \\
\hline USG & 77 & 15.4 & 43 & 8.6 \\
\hline BT & 87 & 17.4 & 43 & 8.6 \\
\hline MR & 41 & 8.2 & 22 & 4.4 \\
\hline EKG & 315 & 73 & 281 & 56.2 \\
\hline
\end{tabular}

Tablo 4: Hastaların ambulans kullanım oranı

\begin{tabular}{|c|c|c|c|c|c|c|c|}
\hline & \multicolumn{3}{|c|}{$\begin{array}{c}\text { AMBULANSLA } \\
\text { GETIRILEN } \\
\text { HASTA }\end{array}$} & \multicolumn{3}{c|}{$\begin{array}{c}\text { AYAKTAN } \\
\text { GELEN HASTA }\end{array}$} & TOPLAM \\
\hline $\mathbf{n}$ & \multicolumn{2}{|c|}{57} & \multicolumn{2}{c|}{443} & 500 \\
\hline$\%$ & \multicolumn{2}{|c|}{11.4} & \multicolumn{2}{c|}{88.6} & 100 \\
\hline & KIRMIZI & SARI & YEŞiL & KIRMIZI & SARI & YEŞİ & TOPLAM \\
\hline $\mathbf{n}$ & 16 & 37 & 4 & 28 & 365 & 50 & 500 \\
\hline$\%$ & 28.07 & 64.91 & 7.02 & 6.32 & 82.39 & 11.29 & 100 \\
\hline
\end{tabular}

Tablo 5: Hastaların hastaneye yatış, sevk ve taburculuk oranlar1

\begin{tabular}{|c|c|c|c|}
\hline & Sonuçlanma & $\mathbf{n}$ & $\%$ \\
\hline Sar alanda tedavi & Yatış endikasyonu olan & 24 & 5.93 \\
\hline 1le taburcu & Yatış endikasyonu olmayan & 381 & 94.07 \\
\hline Servis yatış & & 61 & 12.20 \\
\hline Yoğun bakım yatış & & 16 & 3.20 \\
\hline Personel eksikliği s & & 4 & 0.80 \\
\hline Donanım eksikliği & & 1 & 0.20 \\
\hline Yoğun bakım yatak & yokluğu sevk & 13 & 2.60 \\
\hline Total & & 500 & 100.00 \\
\hline
\end{tabular}

Tablo 6: Kesin tanıya göre tanıların karşılaştııılması

\begin{tabular}{|c|c|c|c|c|}
\hline & Birinci tanı & İkinci tanı & Üçüncü tanı & $\mathrm{p}$ \\
\hline Doğru tanı $\%$ & $64.6^{\mathrm{b}, \mathrm{c}}$ & $76^{\mathrm{a}, \mathrm{c}}$ & $89.2^{\mathrm{a}, \mathrm{b}}$ & $<0.001$ \\
\hline
\end{tabular}

a: Birici tanıya olan farkı gösterir. b: İkinci tanıya olan farkı gösterir. c: Üçüncü tanıya olan farkı gösterir.

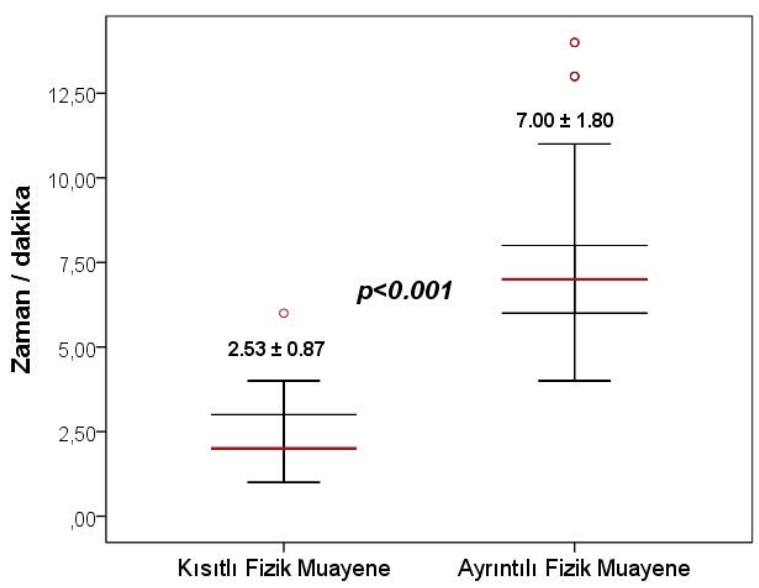

Şekil 1: Kısıtlı ve ayrıntılı fizik muayene zamanları arasında anlamlı fark olduğu görülmektedir.

\section{TARTIŞMA}

Acil servisler, hastane içerisinde oldukça önemli bir yere sahiptirler (8). Amerika Akademik Acil Tıp Birliği’nin önerilerine göre, kritik hastalar için 1:1 oranında, tüm rutin acil hastalar için ise 4:1 oranında hemşire bakımı gereklidir (9). Düşük ve orta aciliyetteki hastaların bulunduğu acil servislerde her hekim için 8-10 yatak bulunmalıdır. Kritik hastalar için ise her hekim için 1-3 yatak bulunmalıdır. En az yatak sayısı ise; $=(1.5 \times 24$ saatte hasta sayısı $\mathrm{x}$ acilde ort.kalış süresi $) /(24$ saat $)$ şeklinde hesaplanmaktadır (9). Dışkapı Yıldııı Beyazıt EAH Acil Servis'inin hasta bakım kapasitesi değerlendirildiğinde acil servisteki bir yatak başına günlük 32 hasta düşmektedir. Bununla beraber acil servisimize başvuran hasta sayısı edinilen veriler ışığında her geçen yıl artmaktadır. Hasta başına düşen hemşire sayısı 0.018 olup, doktor sayıs 0.012 'dir. 2011 WHO istatistiklerine göre ABD'de 1000 kişi başına düşen doktor sayısı 2.7 iken İngiltere'de 2.1 ve Türkiye'de 1.5 , dünya ortalaması ise 3.03 olarak bulunmuş, 1000 kişi başına düşen yatak sayısı ise ABD ve İngiltere'de 3.1 iken Türkiye'de 2.8 olduğu görülmüştür $(5,10)$. Acil servisimizde bir hastaya ayrılan ortalama süre ise $4.3 \mathrm{dk}$ olarak tespit edilmiştir. Bu süre içerisinde hastaya ön tanı konulmakta ve bu ön tanıya göre ileri tetkik ve tedavi uygulanmaktadır. Giderek artan hasta sayıları ve kalifiye eleman eksikliği, hasta değerlendirilme süresini kısaltmaktadır (4). Sağlık ocağı hekimlerine yapılan bir çalışmada, hekimlerin $\% 68.9^{\prime}$ u ilk başvuru yapan hastaların muayenesi için gerekli sürenin 20 dakika, $\% 18.8$ 'i ise 30 dakika olduğunu bildirmişlerdir. Buna karşın hekimlerin sadece \%16'sı bu süreyi ayırabildiklerini belirtirken $\% 73$ 'ü 10 dakika ayırdıklarını söylemişlerdir. Gözlem yapıldığında hekimlerin \%81.9'u ilk değerlendirme için hastalara 5 dakikadan daha az süre ayırmışlardır. Hekimlerin \%50'si geçmiş ve şimdiki şikayete ait tıbbi öyküyü sormamıştır. Hekimlerin \% $\%$ 'i aile öyküsünü almamış ve sistemik muayeneyi yapmamışlardır (11). ABD'de yapılan başka bir çalışmada, hastalara göre birinci basamakta optimal muayene süresinin 15.4 dakika olduğu bildirilmiştir (12). 
Almanya, İngiltere ve ABD'de hekimlerin ilk değerlendirme ve muayene için sırasıyla 6/10/18 dakika ve tam bir fizik muayene için ise sırasıyla 12/20/36 dakika ayırdıkları görülmüştür (13). Çalışmamızda şikayete yönelik kısıtlı fizik muayenenin ortalama zamanı 2.5 dakika tespit edilirken, ayrıntılı fizik muayene ile hastaya ayrılan zaman ortalaması 7 dakika olarak tespit edilmiştir. Çalışmamızda ilk değerlendirme ve muayene süreleri diğer çalışmalara kıyasla kısadır. Yukarıdaki çalışmaların acil servis harici kliniklerde yapılmış olması ve buna karşın çalışmamızın hasta kalabalığının fazla olduğu bir acil serviste yapılması muayene sürelerinin kısa çıkmasında en önemli etkendir. Bizim çalışmamızda şikayete yönelik ön tanı ve kesin tanı arasında \%35.4 oranında bir fark tespit edildi. Bunun nedenleri arasında hastaların kendini ifade edememesi, hastaya ayrılan sürenin yetersiz olması, hastayı değerlendiren kişinin deneyimi ve bilgi birikimi, hastanın başvuru saati ve triyaj için kullanılan sistemler öne çıkmaktadır. Şikayete göre sağlık personelince yapılan ön tanının doğruluğuna bakıldığında Akküçük ve arkadaşlarının yapmış olduğu çalışmada; paramediklerin \%67.1, hemşirelerin \%71.2, intörnlerin \%65, k1demsiz asistanların \%73, k1demli asistanların \%80.8, uzmanların \%84 oranında doğru tanı koydukları görüldü (14). Bizim çalışmamızda ise bu oran \% 64.6 olarak bulundu. Burada şikayetin ve anamnezin alınma süresi de tanıların doğruluğunu etkilemiştir. Eğitim ve araştırma hastanelerinde hasta yoğunluğundan dolayı şikayet ve anamnez alma süreleri de maalesef kısa tutulmaktadır. Oysa Akküçük ve arkadaşlarının çalışması bir üniversite hastanesinde yapılmıştır ve hasta başvuru sayıları daha düşüktür.

Acil servise başvuran hastaların \%52.2'inin kronik hastalığ mevcuttu. Kronik hastalıklara bağlı komplikasyonlar acil servis başvurularında önemli bir yere sahiptir (15). Acil servise başvuru esnasında hastaların kronik hastalarını sorgulamak hastanın değerlendirilmesinde ve tanısında hekime kolaylık sağlayacaktır. Çalışmamızda kısıtlı fizik muayene sonrası oluşan tanı ile ayrıntılı fizik muayene sonrası oluşan tanı arasında \%13.2 fark var idi. Acil servise başvuran hastalarda, hasta değerlendirme ve muayene süresi arttıkça doğru tanı konma oranları artmaktadır.

Kalabalık acil servislerde şikayete yönelik kısıtlı fizik muayene yanlış hasta tanılarına neden olmaktadır. Ambulans ile gelen ve acil servise kabul edilen hastalar ise tüm hastaların \%.11.4'ü idi. Üstelik kırmızı alan acil hasta grubunun yalnızca \%39.86's1 ambulans ile Acil Servisimize getirildi. Çalışmamız süresince acil servise gelen hastaların ambulans kullanma oranı binde 67 idi. Bu oranın 2016 y1lında hastanemiz istatistiklerine göre binde 79 olduğu görülmüştür. Ambulans kullanma oranları; İngiltere'de yılda binde 140, Amerika Birleşik Devletleri'nde (ABD) yılda binde 139 olarak bildirilmiştir $(5,16)$. Bu iki ülkeye göre ambulans kullanma oranımızın halen düşük olduğu görülmektedir. Ayrıca hastalık ciddiyeti yüksek olan hastalar ambulansı beklemeden özel araçları ile acil servislere başvurabilmektedir.

Çalışmamıza alınan hastaların yatış oranı \%15.4 idi. Acil servise başvuran hastaların \% 81'i acil servisten taburcu edildi. Ülkemizde yapılan çalışmalarda acil servisten taburculuk oranları \%82 ile \%86 arasında tespit edilmiştir ve bizim çalışmamızın sonuçları ile uyumludur (17-19).

Acil servis taburculuk oranlarının yüksek olması ülkemizde acil servislere uygunsuz başvuru oranlarının yüksek olduğunu göstermektedir. Ülkemizde acil servis kalabalığ1 sağlık sistemimizin önemli problemlerindendir ve bu durum acil serviste hastaların muayene sürelerinin optimum zamanda yapılmasına engel olmaktadır. Sonuç olarak; Kesin tanıya göre, doğru ön tanı oranlarını belirlediğimizde, hastadan alınan anamnez sonrası, yapılan ayrıntılı muayene ve tetkikler sonucunda doğru tanı oranının arttığını gördük. Acil servisin uygunsuz kullanımına yönelik alınacak tedbirler; gerçek acil hastalarının daha ayrıntılı değerlendirilmesi, tanı ve tedavilerinin gecikmeden yapılması ve dolayısı ile hizmet kalitesinin artmasını sağlayacaktır.

Ek: "14. Ulusal Acil Tip Kongresi 5th Intercontinental Emergency Medicine Congress, International Critical Care and Emergency Medicine Congress, Antalya, Turkey (19-22 April 2018).” Kongresinde poster bildiri şeklinde sunulmuştur.

Çıkar Çatışması: Yazarlar çıkar çatıșması olmadığını beyan etti.

\section{KAYNAKLAR}

1. Cakmak F, Ikizceli I, Ozturk D, Altinbilek E, Yilmaz BK, Biberoglu S, et al. Emergency department length of stay for critically III patients followed up in red zone. Signa Vitae 2021; vol.17(1): 63-68.

2. Hoot NR, Aronsky D. Systematic review of emergency department crowding: causes, effects, and solutions Ann Emerg Med 2008-52(2):126-136

3. Viccellio P, Schneider SM, Asplin B, Blum F, Broida RI, Bukara WR, et al. Emergency department crowding: High impact solutions. ACEP Task Force Report on Boarding 2008.

4. Gill, J. and Riley, A.W. Nonurgent use of hospital emergency departments: urgency from the patient's perspective. The Journel of Family Practice 1996;42(5):491-496.

5. T.C. Sağlık Bakanlığı Sağlık Hizmetleri Genel Müdürlüğü Sağlık İstatistikleri Yıllığı, 2015.

6. Roland MO, Bartholomew J, Courtenay MJ, Morris RW, Morrell DC. The "five minute" consultation: effect of time constraint on verbal communication. Br Med J (Clin Res Ed). 1986;292(6524):874-876.

7. “Kamu Hastaneleri Kurumu: Kaliteli Bir Muayene Süresi En Az 10 dk’dır” Avalaible: http://doktorlarsitesi.net/2016/11/26/kamu-hastane-lerikurumu-kaliteli-bir -muayene-suresi-en-az-10-dkdir/

8. American College of Emergency Physicians Board of Directors1986. Definition of emergency medicine and emergency physician. Ann Emerg Med. 1986;15:1240-1241(Revised and approved by the ACEP Board of Directors June 2015) 


\section{Karsandi et al.}

9. Tandberg D and Qualls C. Time series forecasts of emergency department patient volume, length of stay, and acuity. Ann Emerg Med, 1994; 23(2): 299-306.

10. T.C. Sağlık Bakanlığı Türkiye Kamu Hastaneleri Kurumu İstatistik, Analiz ve Raporlama Daire Başkanlığı, Kamu Hastaneleri İstatistikleri Yıllığı, 2014 Sağlık Bakanlığı Yayın tarihi: Ankara 2015,Yayın No: 1000.

11. Guldal D, Ulusel B, Ozcakar N, Yeniceri N, Dontlu C. The challenge of clinical interviewing and physical examination performance for general practitioners in Turkey. Fam Med. 2005;37(5):354-359.

12. Landau DA, Bachner YG, Elishkewitz K, Goldstein L, Barneboim E. Patients' views on optimal visit length in primary care. J Med Pract Manage. 2007;23(1):12-15.

13. Haroon Siddique. GP appointments should be five minutes longer, says BMA. 2016; https://www.theguardian.com/society/2016/aug/28/doctor-appointments-15-minutes-bma-overweight-population.

14. Akküçük M.H. Kalabalık acil servisler için hasta ve sağlık personeli triyajı. Hacettepe Üniversitesi Tıp Fakültesi, Acil Tıp Uzmanlık Tezi. Ankara, 2010.

15. Derlet RW, Overcrowding in emergency departments: increased demand and decreased capacity. Ann Emerg Med. 2002;39(4): 430-432.

16. Schneider SM. Emergency department crowding. Emergency Medicine Reports. 2009;30(3):13-22.

17. Ersel M, Karcıŏlu Ö, Yanturalı S, Yürüktümen A, Sever M, Tunç MA. Bir Acil Servisin Kullanım Özellikleri ve Başvuran Hastaların Aciliyetinin Hekim ve Hasta Açısından Değerlendirilmesi. Turk J Emerg Med.2006;6(1):25-35.

18. Kılıçaslan İ, Bozan H, Oktay C, Göksu E. Türkiye‘de acil servise başvuran hastaların demografik özellikleri. Turk J Emerg Med.2005;5(1):5-13.

19. Aydın T, Aydın ŞA, Köksal O, Özdemir F, Kulaç S, Bulut M. Uludağ Üniversitesi Tıp Fakültesi Hastanesi acil servisine başvuran hastaların özelliklerinin ve acil servis çalışmalarının değerlendirilmesi. Akademik Acil Tıp Dergisi. 2010;9(4):163-168. 